\title{
Colour development of immunogold-labelled antibodies for light microscopy
}

\author{
P. Fritz ${ }^{1}$, J. Hoenes ${ }^{2}$, J. Schenk ${ }^{2}$, A. Mischlinski ${ }^{1}$, A. Grau ${ }^{1}$, J.G. Saal ${ }^{3}$, H.V. Tuczek ${ }^{1}$, \\ H. Multhaupt ${ }^{1}$, and G. Pfleiderer ${ }^{2}$ \\ ${ }^{1}$ Robert-Bosch-Krankenhaus, Pathologische Abteilung und Abteilung für Hämatologie und Onkologie, D-7000 Stuttgart, \\ Federal Republic of Germany \\ 2 Biochemisches Institut der Universität Stuttgart, D-7000 Stuttgart, Federal Republic of Germany \\ ${ }^{3}$ Medizinische Universitätsklinik Tübingen, Abteilung I, D-7400 Tübingen, Federal Republic of Germany
}

Histochemistry (1986) 85:209-214

Two passages in this article unfortunately contained errors: On p. 209, the sentence starting on line 5 and ending on line 13 of the Introduction should read:

"By combining one of the tested immunohistochemical methods with the immunogold method of Gu et al. (1980), two final reaction products were obtained: brown-red for the peroxidase/anti-peroxidase (PAP) complex and black for the immunogold-labelled antibodies developed using the silver-intensification (SIG) method recently described by several authors (Holgate et al. 1983; Springall et al. 1984;
Hacker et al. 1985; van den Pol 1985). This method is based on the physical development of metallic gold, as described by Danscher (1981 a, b)."

On p. 212, the sentence starting on line 6 and ending on line 10 of the Discussion should read:

"The decisive step in the use of this method in light microscopy, however, was the introduction of silver intensification of the colloidal-gold-labelled secondary antibody or gold-labelled protein-A (Holgate et al. 1983; Springall et al. 1984; Hacker et al. 1985; van den Pol 1985)." 